\title{
Empiema causado por Salmonella typhimurium
}

\author{
MARÍA DEL MAR TACCHINI A.*, ANA CARAFFINI F.**, MARÍA SOLEDAD MONTAMAT C.***, \\ NATALIA SPITALE A.***, YANINA BOSIO D.**** y ANGEL MINGUEZ G.*****
}

\section{Pleural empyema caused by Salmonella typhimurium: A case report}

Salmonella species are commonly associated with acute gastroenteritis due to ingestion of contaminated food or water. Extraintestinal infections are less frequent, and most of them occur in immunocompromised patients. We report a case of pleural empyema caused by Salmonella typhimurium, without previous diarrhea or fever. The patient evolved favorably after receiving adequate treatment.

Key words: Salmonella, pleural empyema.

\section{Resumen}

El género Salmonella se caracteriza por causar infecciones en el tracto gastrointestinal, debido a la ingesta de alimentos o agua contaminada. También puede causar, con menor frecuencia, infecciones localizadas en diferentes órganos; esto se asocia con inmunodepresión. En este caso se describe un paciente con infección pleuropulmonar por Salmonella typhimurium, que no reportó antecedentes de diarrea previa. Evolucionó favorablemente con tratamiento adecuado.

Palabras clave: Salmonella, empiema pleural.

\section{Introducción}

Salmonella spp es un bacilo gram negativo de la familia enterobacteriaceae. El $99,5 \%$ de los aislamientos clínicos corresponden a Salmonella enterica subespecie entérica. Los diferentes serotipos muestran gran variación en su capacidad invasiva para producir enfermedad.

Las formas clínicas de infección por Salmonella suelen dividirse en cinco grupos: fiebre entérica o tifoidea, septicemia sin localización, enfermedad focal (con o sin bacteriemia asociada), gastroenteritis y estado de portador (crónico o transitorio). La infección intestinal es la forma más frecuente de presentación, generalmente se da por ingesta de agua o alimentos contaminados y luego puede diseminarse por contigüidad o por vía sistémica, dando lugar a cuadros infecciosos de localización extraintestinal. Las formas focales pueden localizarse en cualquier órgano luego de una bacteriemia, entre ellos: hueso, pulmones, pleura, meninges, vasos sanguíneos, mesenterio y vesícula biliar. Estas formas se asocian a inmunodepresión y alcoholismo. El compromiso pulmonar por salmonella es raro ${ }^{1-4}$.

\section{Caso clínico}

Paciente de sexo masculino, de 55 años, diabético tipo 2, ex fumador, con hepatopatía alcohólica crónica, hipertensión arterial, y con antecedente de internación por neumonía aguda de la comunidad el 14 de julio de 2008. Recibió tratamiento por 14 días con ceftriaxona, y se le dio de alta el 17 de julio. En diciembre del mismo año ingresó por derrame pleural. Se realizó punción con los siguientes resultados en el análisis físico-químico: aspecto

Hospital Nuestra Señora de la Misericordia. Córdoba. Argentina.

* Licenciada en Bioquímica. Servicio de Laboratorio.

** Licenciada en Bioquimíca Especialista en Bacteriología. Servicio de Laboratorio.

*** Médico. Servicio de Infectología.

**** Médico. Servicio de Clínica Médica.

***** Médico Infectólogo. Servicio de Infectología. 
turbio; color: pardo-rojizo; sangre: ++++; coágulos: +++; pH: 7,5; densidad: 1.020; glucosa: 73 $\mathrm{mg} / \mathrm{dL}$; LDH: $818 \mathrm{mg} / \mathrm{dL}$; proteínas totales: 4,1 $\mathrm{mg} / \mathrm{dL}$. Se aplicaron los criterios de Light dando como resultado un derrame pleural exudativo. El paciente solicitó alta voluntaria el 30 de diciembre, previo a llegar a un diagnóstico etiológico.

El 23 de enero de 2009 consulta por omalgia izquierda, disnea progresiva y tos productiva de un mes de evolución. Al examen físico: normotenso, taquipneico, afebril, con semiología de derrame hasta tercio medio del campo pulmonar izquierdo. Exámenes de laboratorio: leucocitos $9.700 / \mathrm{mm}^{3}$, fórmula leucocitaria: neutrófilos: 70\%, eosinófilos: 3\%, basófilos: $0 \%$, linfocitos: $15 \%$, monocitos: $5 \%$; hematocrito: $31,2 \%$, hemoglobina: $11,4 \mathrm{mg} / \mathrm{dL}$, glicemia $225 \mathrm{mg} \%$, creatininemia $0,75 \mathrm{mg} \%$, gasometría arterial: pH: 7,448 $\mathrm{PCO}_{2}: 28,8 \mathrm{mmHg} ; \mathrm{PO}_{2}: 78,7 \mathrm{mmHg}$, bicarbonato: $20,4 \mathrm{mEq} / \mathrm{L}$; $\mathrm{BE}:-3 \mathrm{mEq} / \mathrm{L}$, saturación de la hemoglobina con $\mathrm{O}_{2}: 96 \%$. Radiografía de tórax: opacidad en dos tercios inferiores del campo pulmonar izquierdo (Figura 1). Ecografía pleural: derrame de alta densidad en dicho pulmón. Se realiza punción evacuadora drenando $1.300 \mathrm{~mL}$ de material purulento achocolatado,

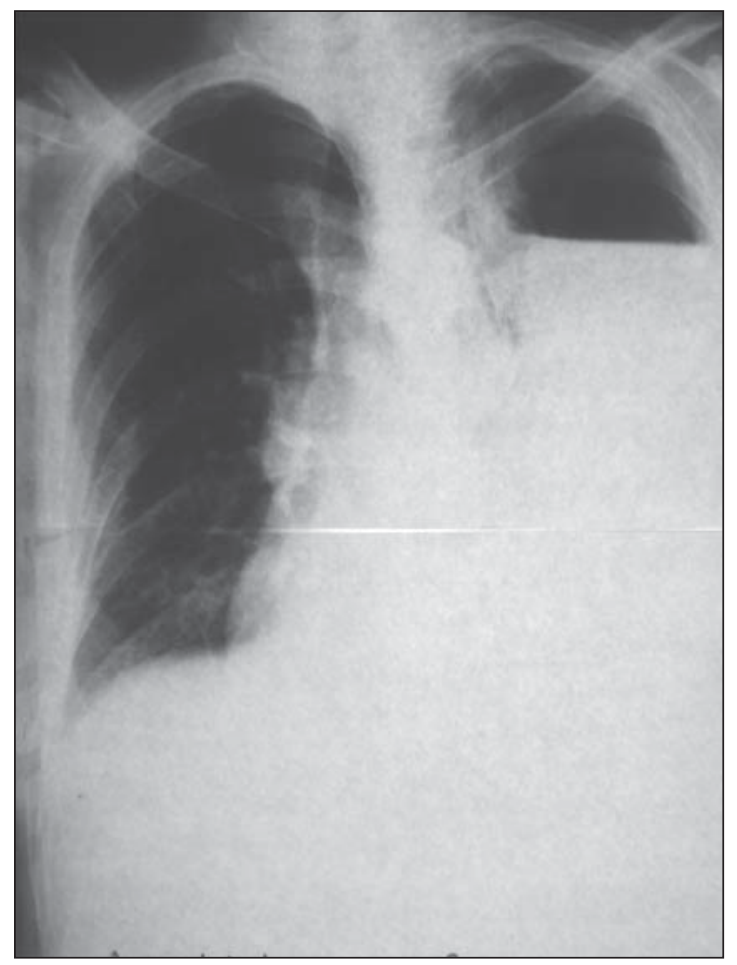

Figura 1. Radiografía de tórax en proyección pósteroanterior (23.01.2009). Opacidad con nivel horizontal que ocupa los dos tercios inferiores del hemitórax izquierdo, correspondiente a empiema pleural (ver texto). maloliente. Se solicitan múltiples cultivos y se inicia tratamiento con ampicilina/sulbactam (AMS) en forma empírica por diagnóstico de empiema pleural.

El paciente evoluciona afebril. Se le coloca tubo de drenaje, y se aumenta la dosis de AMS a 3 g. Anatomía Patológica informa: líquido pleural negativo para malignidad.

En la tinción de Gram directa se observó más de 50 leucocitos por campo y regular cantidad de bacilos Gram negativos (BGN). A las $24 \mathrm{~h}$ el cultivo desarrolló BGN que se tipificaron por pruebas bioquímicas (Tabla 1) resultando Salmonella spp. Se confirmó con el sistema Api 20 E (Biomérieux).

Para la serotipificación se derivó la cepa al Instituto de Referencia ANLIS Malbran, que la clasificó como Salmonella enterica subespecie entérica serovariedad typhimurium. Se realizaron estudios de sensibilidad por técnica de difusión en agar según Kirby Bauer y normas del CLSI (Medio Mueller Hinton de Biomérieux, discos Oxoid), con los siguientes resultados: Sensible a: gentamicina, cefalotina, ciprofloxacina, amicacina, amoxicilina-clavulánico, cefotaxima, ceftazidima, meropenem, imipenem, piperacilina-

Tabla 1. Resultado de las pruebas bioquímicas de tipificación

\begin{tabular}{|lc|}
\hline Agar TSI & Ácido/alcalino \\
\hline Urea & - \\
\hline Citrato & + \\
\hline Indol & - \\
\hline Fenilalanina & - \\
\hline ONPG & - \\
\hline Lisina & + \\
\hline Ornitina & + \\
\hline Arginina & + \\
\hline Sorbitol & - \\
\hline Rafinosa & - \\
\hline Ramnosa & + \\
\hline Arabinosa & + \\
\hline Manosa & + \\
\hline Trehalosa & + \\
\hline Adonitol & - \\
\hline Sucrosa & - \\
\hline Manitol & + \\
\hline SH & + \\
\hline
\end{tabular}


tazobactam. Resistente a: ampicilina, ampicilinasulbactam.

El 28 de enero se agregó al tratamiento del paciente ciprofloxacina intravenosa y se suprimió AMS, según los resultados de sensibilidad recibidos del laboratorio.

Los cultivos de sangre y orina resultaron negativos. Se realizó ecografía abdominal: hígado de ecogenicidad no homogénea, vena porta de 14 $\mathrm{mm}$, vesícula de paredes engrosadas (hallazgo esperado en paciente con ascitis), sospecha de litiasis, colédoco normal. Líquido libre. Resto sin particularidades.

Se realiza paracentesis abdominal. El estudio del líquido obtenido resulta estéril con características de transudado compatible con síndrome ascítico edematoso y se instaura tratamiento para el mismo.

Se realiza tomografía axial computada de tórax observándose derrame pleural derecho escaso, franco engrosamiento pleural izquierdo con tubo de drenaje.

Serología: Virus de hepatitis C negativo; Virus Inmunodeficiencia Humana negativo; Virus hepatitis B Ag anti core, y Ac anti HBs: reactivos. Se interpreta como infección previa resuelta.

El 29 de enero el paciente presenta abdomen distendido blando no doloroso. Por la imagen ecográfica y los análisis de laboratorio se diagnostica litiasis vesicular y síndrome anémico.

El paciente evolucionó favorablemente. No obstante el 9 de febrero se le realizó punción abdominal, extrayéndose 2 litros de líquido ascítico al cual se le realizaron estudios físico-químicos y bacteriológicos. El estudio físico-químico de dicho material se encontró dentro de los parámetros normales de transudado. Los resultados bacteriológicos mostraron una tinción de Gram del directo, sin leucocitos ni gérmenes y en el cultivo no hubo desarrollo de microorganismos. El paciente evolucionó favorablemente, se retiró el tubo de drenaje, cumplió seis semanas de tratamiento con ciprofloxacina y fue dado de alta el 23 de febrero de 2009. No concurriendo a los controles posteriores de seguimiento.

\section{Discusión}

Las formas clínicas focales por Salmonella spp fueron descritas por primera vez por Artaud en 1885, han suscitado creciente interés recientemente debido al aumento en pacientes con SIDA e inmunodeprimidos ${ }^{5,6}$. En las bacteriemias y formas focales se ha otorgado gran importancia, en diversos estudios a la edad como factor pre- disponente, con predominio de edades superiores a 50 años ${ }^{7}$.

La patogenia de Salmonella comienza con ingestión de un inóculo elevado de microorganismos; adherencia al enterocito, fosforilación de receptor EGF: cambios drásticos en la concentración de $\mathrm{Ca}^{2+}$ intracelular, reorganización del citoesqueleto de actina; internalización; supervivencia dentro de las vacuolas fagocíticas, liberación de enterotoxinas, translocación hacia la lámina propia, disparo de la respuesta quimiotáctica, e infección local o regional. La infección sistémica se produce debido a que pueden sobrevivir dentro de las vacuolas fagocíticas de los macrófagos resistiendo la acción de las enzimas lisosomales.

La acidez gástrica, la motilidad intestinal normal y la flora habitual del intestino son mecanismos inespecíficos de defensa contra la infección. Los específicos contra Salmonella spp, no son aún completamente conocidos, pero la función de los macrófagos se ha demostrado importante ${ }^{11}$.

Probablemente el sitio primario de infección haya sido una intoxicación alimentaria autolimitada, desde donde la bacteria alcanzó la circulación sanguínea causando bacteriemia, con la posibilidad de que los bacilos se encuentren latentes en el sistema retículo endotelial, con posterior reactivación o bien, se acantonó en la vesícula biliar, afectada por una litiasis, y luego a través del torrente sanguíneo pudo migrar al pulmón, provocando el empiema ${ }^{10}$.

La presentación suele ser aguda, con evolución desfavorable. Las manifestaciones clínicas y radiológicas suelen ser indistinguibles de la infección causada por otros microorganismos. En el caso narrado no hubo historia de diarrea, y los cultivos de orina, sangre y líquido ascítico fueron negativos. Los factores predisponentes fueron la edad (mayor a 50 años) y el hábito etílico. Esto coincide con otros casos reportados en la bibliografía ${ }^{8,9}$.

En conclusión, aunque excepcional, debe considerarse que una Salmonella spp puede ser un agente causal de infección pleuropulmonar en pacientes inmunocomprometidos, con enfermedad subyacente e incluso en ausencia de compromiso gastrointestinal evidente ${ }^{10}$.

\section{Bibliografía}

1.- CARRADA BRAVO T. Fiebre tifoidea: caso clínico, estudio epidemiológico, patogenia, diagnóstico y tratamiento. Med Int Mex 2007; 23: 447-57.

2.- RODRÍGUEZ C H, DE MIER C, BOGDANOWICZ 
E, CAFFER M I, GARCÍA S, LASALA M B, et al. Salmonelosis extraintestinal: clínica, epidemiología y resistencia antimicrobiana. Acta Bioquím Clín Latinoam 2007; 41: 379-83.

3.- SEPTIMUS E. Derrame pleural y Empiema. En: Mandell G, L. Enfermedades Infecciosas. Principios y prácticas. $6^{\text {ta }}$ Edicion. Madrid. Ed: Elsevier España S.A. 2006; 845-52.

4.- WINN W, ALLEN S, JANDA W, KONEMAN E, PROCOP G, SCHRENCKENBERGER P, et al. Enterobacteriaceae. En: Koneman E, W. Diagnóstico microbiológico: Texto y atlas en color. $6^{\text {ta }}$ Edición. Buenos Aires. Ed. Médica Panamericana 2008; 204-80.

5.- AGUADO J M, RAMOS J M, GARCÍA-CORBEIRA P, ALES J M, FERNÁNDEZ-GUERRERO M L, SORIANO F. Espectro clínico de la infección focal por Salmonella no typhi, experiencia en 32 años. Med Clin (Barc) 1994; 103: 293-8.

6.- KANUNGO R, KUMAR A, SRINIVASAN S, BADRI-
NATH S. Pleural empyema due to group B Salmonella in a child with diarrea. Indian Pediatrics 2001; 38: 1869.

7.- REMACHA ESTERAS M A, PARRA PARRA I, SANTOS CALDERÓN J A. Empiema pleural por Salmonella enteritidis. Arch Bronconeumol 2002; 38: 341.

8.- GARCÍA CLEMENTE M, HIDALGO GARCÍA F, GONZÁLEZ BUDIÑO T. Derrame pleural neoplásico infectado por Salmonella enteritidis (Cartas al Director). An Med Interna (Madrid) 2004; 21 (12): 54-5.

9.- SEGADO A, QUERO F, VIDAL J L, POZA A, VILALTA E, NAVARRO C, et al. Neumonía necrotizante por Salmonella en paciente etílico. (Cartas al Director). An Med Interna (Madrid) 2003; 20 (2): 60-1.

10.- VAISHNAVI C, KOCHHAR R, SINGH G, KUMAR S, SINGH S, SINGH K. Epidemiology of typhoid carriers among blood donors and patients with biliary, gastrointestinal and other related diseases. Microbial Immunol 2005; 49: 107-12.

Correspondencia a:

María del Mar Tacchini A.

Hospital Nuestra Señora de la Misericordia.

Belgrano 1500, Córdoba, Argentina

E-mail: mmtacchini@hotmail.com 